\title{
Investigation of Dry Granulation and Wet Granulation Effect on Dissolution Profile of the Developed Film Coated Tablets Containing Eplerenone
}

\author{
Elin İlayda Deniz*, Cüneyt Toprak, and Gökay Gün \\ Research and Development Department, World Medicine Illaç San ve Ticaret A.Ş., Istanbul, Turkey
}

*Corresponding author: Elin İlayda Deniz, Research and Development Department, World Medicine Illaç San ve Ticaret A.Ş., Istanbul, Turkey, E-mail: ilayda.deniz@worldmedicine.com.tr

Received: 06 Sep, 2021 | Accepted: 20 Sep, 2021 | Published: 25 Sep, 2021

Citation: Deniz Ei, Toprak C, Gün G (2021) Investigation of Dry Granulation and Wet Granulation Effect on Dissolution Profile of the Developed Film Coated Tablets Containing Eplerenone. J Drug Res Dev 7(2): dx.doi.org/10.16966/2470-1009.164

Copyright: (c) 2021 Deniz Ei, et al. This is an open-access article distributed under the terms of the Creative Commons Attribution License, which permits unrestricted use, distribution, and reproduction in any medium, provided the original author and source are credited.

\begin{abstract}
The objective is to observe and improve drug release of Eplerenone which is BCS Class II API by applying dry granulation and wet granulation process. Inspra $50 \mathrm{mg}$ film coated tablets, manufactured by Pfizer, were taken as reference product to compare with dissolution profiles of dry granulation applied product and wet granulation applied product. Investigation of the effect of wet granulation process on dissolution profiles of Eplerenone 50 $\mathrm{mg}$ film coated tablets has been demonstrated out in the scope the study. While $\mathrm{f} 2$ similarity factor is 44.93 for dry granulation applied product, it is 60.62 for wet granulation applied product when compared to reference product. It comply that dissolution rate of wet granulation applied product is more proper to the specification than dry granulation applied product. The study demonstrates the effect of different granulation process on dissolution rate.
\end{abstract}

Keywords: Wet granulation; Dry granulation; Dissolution; Eplerenone

\section{Introduction}

Eplerenone with the CAS registry number of 107724-20-9 is a Selective Aldosterone Receptor Antagonist (SARA) and used for treatment of the patients with chronic heart failure and high blood pressure caused by resistant hypertension due to elevated aldosterone. The molecular formula and weight of Eplerenone are $\mathrm{C}_{24} \mathrm{H}_{30} \mathrm{O}_{6}$ and 414.49 respectively [1].

Within the Biopharmaceutics Classification System (BCS), Eplerenone is class-II Active Pharmaceutical Ingredient (API) [2]. It is off-white to white powder which is soluble in Dichloromethane, slightly soluble in Methanol and insoluble in water [1]. The structure of the Eplerenone molecule is shown in below as figure 1. Eplerenone is found as tablet form with $25 \mathrm{mg}$ and $50 \mathrm{mg}$ dosage in the market and supplied from Pfizer as Inspra $25 \mathrm{mg}$ film coated tablets and Inspra $50 \mathrm{mg}$ film coated tablets.

Combination of small particles with the help of mechanical force or a binding agent to form granules is called granulation in the pharmaceutical industry. It is important for improving API's ultimate utility and controlling the release rate of the active ingredient. The purposes of the granulation can be described as follows; improving the flow characteristic of the mixture, preparing homogeneous mixtures that will not disperse over time and improving compaction [3]. Dry granulation and wet granulation are most common granulation methods for solid dosage forms.

Dry granulation is forming granules without using a liquid solution. The process is applying for products which are sensitive to moisture and heat. It can be done in two ways as slug compression or compactor. Slug compression process is done by pressing and crushing tablets (briquettes) in order to make powder mixtures whose flowability is not suitable for the tablet pressing process to granules. Compactor is the process of obtaining granules by compacting the powder with two rollers, obtaining briquettes in strips and grinding them $[4,5]$.

Wet granulation is forming granules by adding a liquid solution to powder. Solvent that is used in granulation should be volatile, e.g. water, ethanol and isopropanol. The process helps to reduce segregation possibility by binding excipient with API. This method yields better flowability to a formulation. Wet granulation takes advantages of being robust process suitable for most compounds against dry granulation. Low shear granulation, high shear granulation and fluid bed granulation are type of granulation. Selection of the method depends on physicochemical properties of the API and excipients, required flow and release properties $[4,5]$.

Considering the fact that almost $40 \%$ of pharmaceuticals in the 
<smiles>COC(=O)C1CC2=CC(=O)CCC2(C)C2C1CC1(C)CC3(CCC(=O)O3)CCC21</smiles>

Figure 1: Structure of the Eplerenone molecule [1].

market and $90 \%$ of the pharmaceuticals in the development stage have poor solubility in water, dissolution, which is drug release, is one of the key phenomena for producing pharmaceuticals and developing new formulations of drugs [6,7]. Drug dissolution for solid dosage forms should be occurring in appropriate manner and can be expressed as the dissolved amount of drug as a function of the test time. The criterion for the similarity between two in vitro dissolution profiles is defined as similarity factor (f2) by Center for Drug Evaluation and Research (CDER) and human medicines evaluation unit of the European agency (EMEA). In general f2values higher than 50 (50-100) shows the similarity of the dissolution profiles. The factors that affect dissolution are as follows; [8-10]

$>$ Solubility,

> Polymorphic form,

> Particle size,

$>$ Amount in the drug dosage form [8],

$>$ Surface active agents,

The effect of surface active agents on dissolution is taken into account while determining the limits of the physical stability of the preparation [11]. As an anionic surfactant Sodium Lauryl Sulphate (SLS) is used as wetting agent in solid dosage forms [12]. Sodium lauryl sulphate has the effect of increasing on the dissolution rate [13].

\section{Materials}

Active substance and excipients that are included in the formulation, their functions and suppliers are described in table 1 [12]. The same unit formula used for both dry and wet granulation methods to be able to see effect of different production methods on dissolution profile clearly. Since the critical substance that have effect on increment of the dissolution rate is SLS, the same amount of SLS was used for both wet granulation and dry granulation applied developed product as the amount in the reference product in order to make a fair comparison between the results of two different methods.

\section{Methods}

Development of the formulation of Eplerenone $50 \mathrm{mg}$ film coated tablets has been carried out with two different methods; dry granulation which is trial 1 and wet granulation which is trial 2. Both dry and wet granulation methods had been applied to same unit formula. Inspra 50 $\mathrm{mg}$ film coated tablets are taken as reference product.

\section{Trial 1}

Eplerenone, lactose monohydrate, croscarmellose sodium, hypromellose, and avicel $\mathrm{PH}-102$ were sifted with $0.6 \mathrm{~mm}$ sieve and mixed in the Qubic mixer at $60 \mathrm{rpm}$ for 15 minutes. Sodium lauryl sulphate was sifted with $0.6 \mathrm{~mm}$ sieve and added to the first mixture and mixed for 10 minutes. Talc and Magnesium stearate were sifted with $0.5 \mathrm{~mm}$ sieve and added to the second mixture separately and mixed for 3 minutes. Slug compression is applied by compressing, crushing and compressing tablets respectively. The dispersion of Opadry yellow, which is Hydroxypropyl Methyl Cellulose (HPMC) based film coating material, in purified water is prepared for coating process, mixed at $500 \mathrm{rpm}$ for 30 minutes. Core tablets that compressed in accordance with their specifications are coated with Opadry yellow dispersion. Film coating is applied till $10 \mathrm{mg}$ coating is done. Flow diagram of the process is shown in figure 2 .

\section{Trial 2}

Eplerenone, lactose monohydrate, croscarmellose sodium, microcrystalline cellulose and hypromellose were mixed in the high shear granulator. Sodium lauryl sulphate dissolved in purified water. Granulation is done by adding solution to the mixed powder. Wet granules dried at $45^{\circ} \mathrm{C}$ in fluid bed dryer. The loss on drying value was checked with Infrared moisture analyzer and is not more than $3 \%$. Dry granules were sifted with $0.8 \mathrm{~mm}$ Frewitt sieve. Microcrystalline cellulose added to the dry granules and mixed in Qubic mixer for 10 minutes at $60 \mathrm{rpm}$. Talc and magnesium stearate, which were sifted

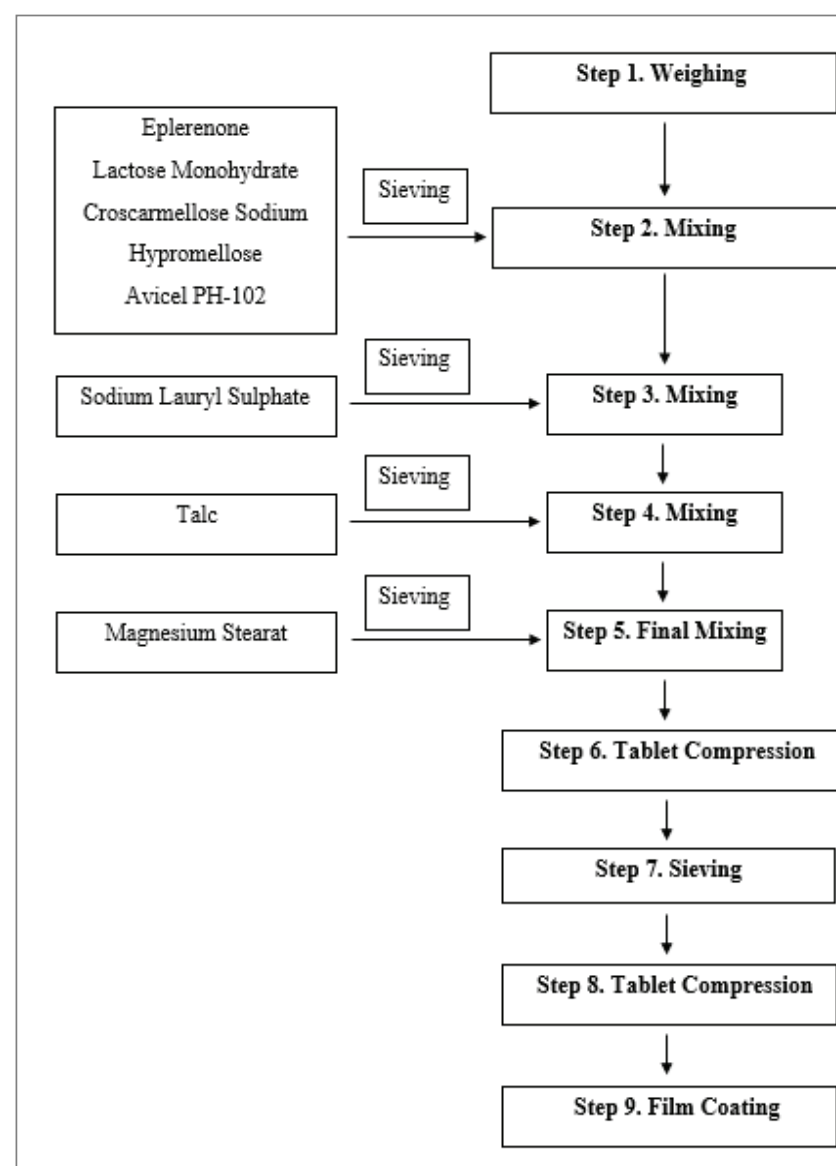

Figure 2: Flow diagram of dry granulation method (SLUG compression process). 
Table 1: Formulation of the Eplerenone $50 \mathrm{mg}$ film coated tablets.

\begin{tabular}{|c|c|c|c|}
\hline Materials & Unit Formula* (mg) & Function & Supplier \\
\hline \multicolumn{4}{|l|}{ Active Substance } \\
\hline Eplerenone & 50.00 & Active Substance & MSN \\
\hline \multicolumn{4}{|l|}{ Excipients } \\
\hline Lactose Monohydrate & 71.40 & Diluent & MEGGLE \\
\hline Sodium Lauryl Sulphate & 1.70 & Surfactant & HUNSTMAN \\
\hline Croscarmellose Sodium & 8.50 & Disintegrant & DUPONT \\
\hline Hypromellose & - & Binder & COLORCON \\
\hline Microcrystalline Cellulose & - & Filling Agent & DUPONT \\
\hline Talc & - & Lubricant & LUZENAC \\
\hline Magnesium Stearate & - & Lubricant & PETER GREVEN \\
\hline Core Tablet Weight & - & & \\
\hline Opadry Yellow & 10.00 & Coating Agent & COLORCON \\
\hline Pure water ${ }^{1}$ & - & - & - \\
\hline Film Coated Tablet Weight & - & & \\
\hline
\end{tabular}

${ }^{1}$ Not found in finished product.

*As a company policy, we cannot share the unit formula.

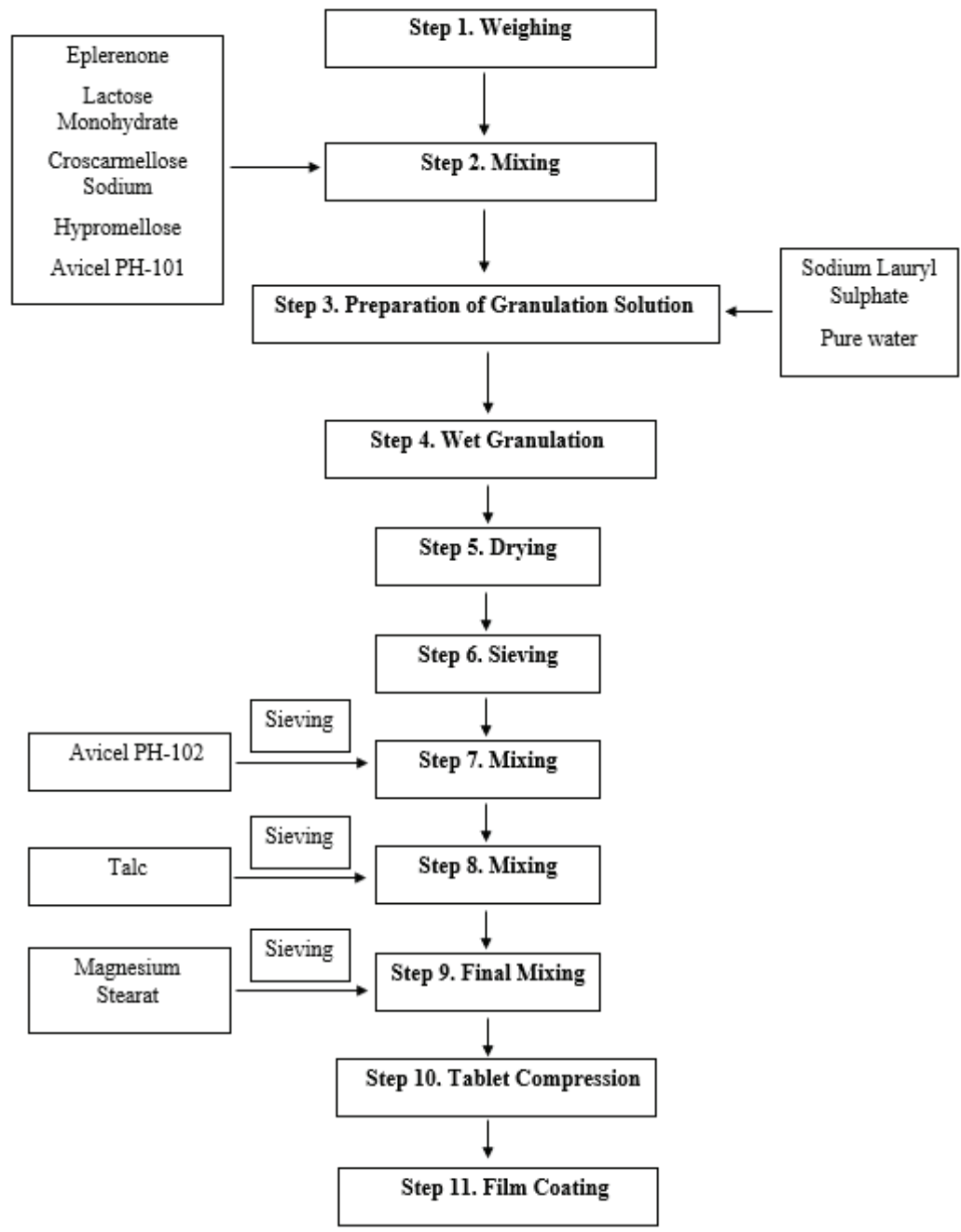

Figure 3: Flow diagram of wet granulation method. 
with $0.5 \mathrm{~mm}$ sieve, added to dry granules one by one and mixed for 3 minutes respectively. Core tablets are compressed in accordance with their specifications and coated $10 \mathrm{mg}$ with Opadry yellow dispersion. Flow diagram of the process is shown in figure 3.

\section{Results and Discussion}

In the scope of the study, dissolution test was applied on both reference product which is Inspra $50 \mathrm{mg}$ film coated tablets and Eplerenone $50 \mathrm{mg}$ film coated tablets which are produced by applying two different methods that are dry granulation and wet granulation.
Chromatographic conditions for dissolution are as given in table 2 according to the European Pharmacopoeia (EP) monograph 2.9.3. The method used for Eplerenone amount determination is based on European Pharmacopoeia (EP) monograph 2.2.25. The instruction is 'minimum $80 \%$ of label claim in 30 minutes' $[14,15]$.

The results of dissolution rate profiles of reference product and dry granulation applied product and wet granulation applied product are given in the table 3 and table 4 , respectively. Besides, comparison of dissolution rate profiles of reference product $v s$. dry granulation

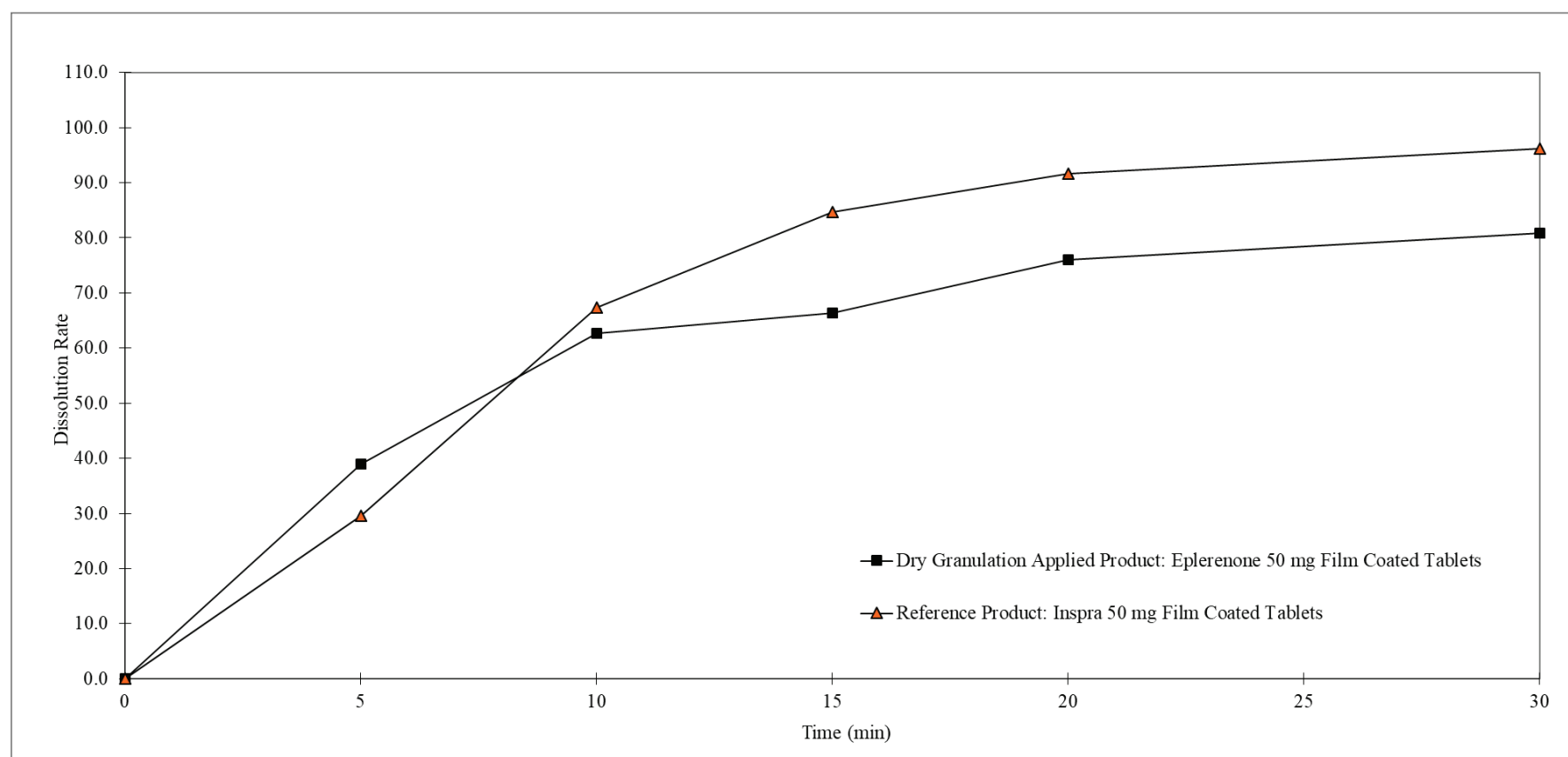

Figure 4: Comparison of dissolution rate profiles of reference product vs. dry granulation aplied product.

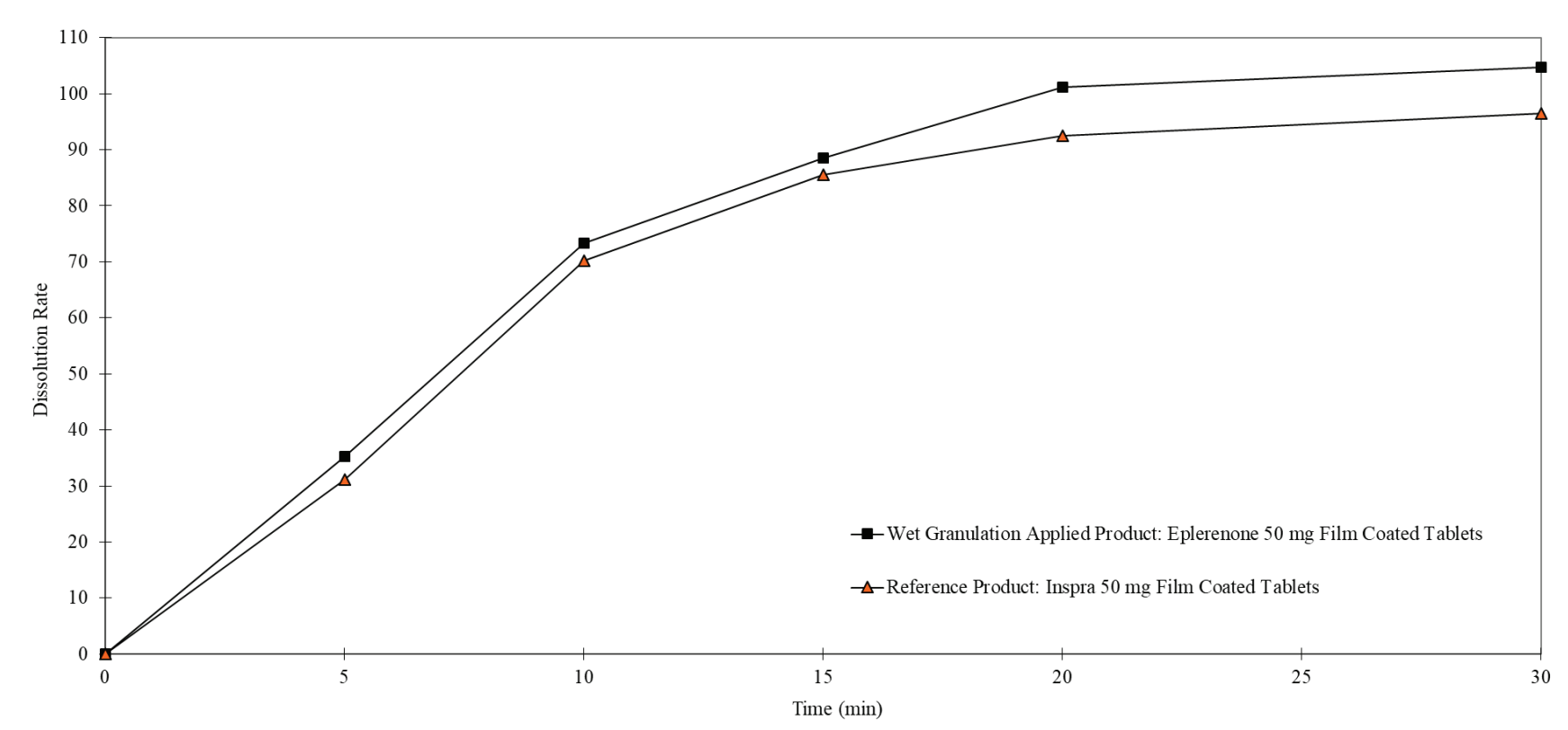

Figure 5: Comparison of dissolution rate profiles of reference product vs. wet granulation aplied product. 
Table 2: Chromatographic conditions.

\begin{tabular}{|l|l|}
\hline \multicolumn{1}{|c|}{ Used device } & \multicolumn{1}{c|}{ UV spectrophotometer } \\
\hline Wavelength & UV, $245 \mathrm{~nm}$ \\
\hline Dissolution medium & $0.1 \mathrm{~N} \mathrm{HCl}$ \\
\hline Volume of dissolution medium & $1000 \mathrm{ml}$ \\
\hline Temperature of dissolution medium & $370 \mathrm{C} \pm 0.5$ \\
\hline Stirring speed & $50 \mathrm{rpm}$ \\
\hline Apparatus & Pedal \\
\hline Time & 30 minutes \\
\hline
\end{tabular}

Table 3: Results of dissolution rate profiles of reference product and dry granulation applied product.

\begin{tabular}{|l|c|c|c|c|c|c|}
\hline \multicolumn{1}{|c|}{ Time (Minute) } & $\mathbf{0}$ & $\mathbf{5}$ & $\mathbf{1 0}$ & $\mathbf{1 5}$ & $\mathbf{2 0}$ & $\mathbf{3 0}$ \\
\hline $\begin{array}{l}\text { Product (\%) } \\
\text { Eplerenone 50 mg film } \\
\text { coated tablets }\end{array}$ & 0.0 & 38.96 & 62.62 & 66.41 & 76.02 & 80.85 \\
\hline $\begin{array}{l}\text { Reference Product (\%) } \\
\text { Inspra 50 mg film coated } \\
\text { tablets }\end{array}$ & 0.0 & 29.51 & 67.42 & 84.72 & 91.66 & 96.21 \\
\hline
\end{tabular}

Table 4: Results of dissolution rate profiles of reference product and wet granulation applied product.

\begin{tabular}{|l|c|c|c|c|c|c|}
\hline \multicolumn{1}{|c|}{ Time (Minute) } & $\mathbf{0}$ & $\mathbf{5}$ & $\mathbf{1 0}$ & $\mathbf{1 5}$ & $\mathbf{2 0}$ & $\mathbf{3 0}$ \\
\hline $\begin{array}{l}\text { Product (\%) } \\
\text { Eplerenone 50 mg film } \\
\text { coated tablets }\end{array}$ & 0.0 & 35.23 & 73.29 & 88.47 & 101.12 & 104.71 \\
\hline $\begin{array}{l}\text { Reference Product (\%) } \\
\text { Inspra 50 mg film coated } \\
\text { tablets }\end{array}$ & 0.0 & 31.16 & 70.17 & 85.59 & 92.51 & 96.54 \\
\hline
\end{tabular}

aplied product and comparison of dissolution rate profiles of reference product $v s$. wet granulation aplied product are given in the graphsfigure 4 and figure 5 , respectively.

The results should be considered according to specification which is 'minimum $80 \%$ of label claim in 30 minutes'. According to results on the table $3,96.54 \%$ of reference product dissolves in 30 minutes. However, $80.85 \%$ of dry granulation applied product dissolves in 30 minutes. Even the result comply the specification, it is still not approximate the dissolution rate of reference product which is $96.54 \%$, which is undesired situation. Also, the graph of comparison of dissolution rate profiles of reference product versus dry granulation aplied product shows the differences between profiles clearly. It explains that the f2 similarity factor, which is 44.93 , is not suitable.

According to the dissolution rate results of the wet granulation applied product as shown in table $4,104.71 \%$ of product dissolves in 30 minutes while $96.54 \%$ of reference product dissolves in 30 minutes. With the increasement of the dissolution of tablets of wet granulation applied produt, $\mathrm{f} 2$ similarity factor, which is 60.62 , to reference produt is also increased.

\section{Conclusion}

The effect of the wet granulation process on dissolution profile of Eplerenone $50 \mathrm{mg}$ film coated tablets is investigated by comparing both dissolution rate results of dry granulation and wet granulation. Dissolution rate results of the products were compared with the dissolution rate of the reference product. While dissolution is 80.85 for dry granulation applied product, it is 104.71 for wet granulation applied product within 30 minutes. Similarity factor f2 is 44.93 and 60.62 for dry granulation applied product and wet granulation applied product, respectively. The results demonstrate that drug release of wet granulation applied product occur in more appropriate manner when compared with dry granulation applied product. The study shows that besides the effects of solubility, polymorphic form, particle size, amount in the drug dosage form and surface active agents, different manufacturing process are also have significant effect on dissolution rate.

\section{Acknowledgement}

The study was supported by World Medicine İlaç San. ve Ticaret A.Ş.

\section{References}

1. Drug master file of Eplerenone, MSN, Version: PL/AP-ROW/03/09-15.

2. Khames A (2019) Formulation and characterization of eplerenone nanoemulsion liquisolids, an oral delivery system with higher release rate and improved bioavailability. Pharmaceutics 11: 40.

3. Aulton ME, Taylor MG (2007) Aulton's Pharmaceutics: The design and manufacture of Medicine. $3^{\text {rd }}$ Edition, Churchill Livingstone, United Kingdom 410-417.

4. Jannat E, Al Arif A, Hasan MM, Zarziz AB, Rashid HA (2016) Granulation techniques \& its updated modules. Pharma Innov 5: 134-141.

5. Parikh DM (2009) Handbook of Pharmaceutical Granulation Technology, Third Edition. Taylor \& Francis, United Kingdom.

6. Butt S, Hasan SMF, Hassan MM, Alkharfy KM, Neau SH (2019) Directly compressed rosuvastatin calcium tablets that offer hydrotropic and micellar solubilization for improved dissolution rate and extent of drug release. Saudi Pharm J 27: 619-628.

7. Cascone $S$ (2017) Modeling and comparison of release profiles: Effect of the dissolution method. Eur J Pharma Sci 106: 352-361.

8. Costa P, Sousa Lobo JM (2001) Modeling and comparison of dissolution profiles. Eur J Pharm Sci 13: 123-133.

9. United States Pharmacopeial Convention (2009) United States Pharmacopeia [and] National Formulary. Volume 2. United States Pharmacopeial Convention, United States.

10. USFDA (2009) Q8 (R2) Pharmaceutical Development.

11. Taylor Jr PW, Wurster DE (1965) Dissolution kinetics of certain crystalline forms of prednisolone II: Influence of low concentrations of sodium lauryl sulfate. J Pharm Sci 54: 1654-1658.

12. Rowe RC, American Pharmacists Association (2009) Handbook of pharmaceutical excipients. $6^{\text {th }}$ Edition, Pharmaceutical Press, United Kingdom 651-652.

13. Levy G, Gumtow RH (1963) Effect of Certain Tablet Formulation Factors on Dissolution Rate of the Active Ingredient I11. J Pharm Sci 52: 1139-1144.

14. Council of Europe (2010) European Pharmacopoeia. $7^{\text {th }}$ Edition, Council of Europe, France.

15. USFDA (2011) Q4B Annex 7 (R2) Dissolution Test General Chapter. 